JOURNAL

OF THE

\title{
ROYAL MICROSCOPICAL SOCIETY.
}

APRIL 1895.

TRANSACTIONS OF THE SOCIETY.

IV.-Monochromatic Violet.

By J. WiLliam Gifford, F.R.M.S.

(Read 19th December, 1894.)

PLATE!I.

Some of the Fellows will perhaps remember that this time last year I brought to their notice a malachite-green screen. Since then I have been taking photographs of absorption spectra, in the hope of being able to construct an equally efficient violet screen. This is now accomplished, and the screen has in great measure failed, though the failure is not, I venture to think, from any inherent faults of its own. But before stating where the fault lies, let me describe this screen.

If the sun's rays, after passing throngh a saturated solution of methyl-violet, be examined by a small spectroscope, it will be found that all rays in the solar spectrum from line $B$ to a position between lines $F$ and $G$ have been absorbed. 'The remaining spectrum consists of a narrow red band and a broad violet band. If solutions of ethylviolet and gentian-violet be used much the same effect is obtained; but with the former the violet band extends more into the blue and is broader, with the latter it extends less into the blue and is narrower.

If we impress such a spectrum (methyl-violet) on a photographic plate sensitive to all colours, it will be seen that the violet band extends into the ultra-violet beyond $\mathrm{H}_{1} \mathrm{H}_{2}$ (plate $\mathrm{I}$. fig. 1 ).

On placing a piece of the blue glass known as signal-green behind the solution, and again looking through our spectroscope, it will be seen that the red band is cut off, and if a photograph be taken the invisible violet beyond the $H$ lines also disappears, a band of more or less visible violet alone remaining (plate I. fig. 2).

The solution, made by preference with glycerin and the blue glass, may without much trouble be combined in one mount. I have adopted this form lately for the malachite-green screen, using the blue glass instead of picric acid to get rid of the ultra-violet, for I found that sooner or later the picric acid combined with the cement. 
Having described the violet screen I will now show you a photograph of the spectrum taken tbrough it on a bromide film, such as is used for ordinary lantern-slide work (plate I. fig. 3).

Immediately below is the spectrum taken on such a plate without any screen (plate I. fig. 4).

You will see that if a line be drawn through the centre of both, it will occupy very nearly the same position. And if lines be drawn representing the mean of average intensity, they will be still more nearly in the same relative position.

The deduction is sufficiently obvious. We can focus our micrcobjective or astro-telescope or photographic lens with such a screen, and then remove the screen altogether for the exposure, and this has been borne out in practice.

But the difficulty comes in here. You have before you a photograph of the Podura scale, taken in this way with a Powell and Lealand semiapochromatic of 1.5 N.A. (plate I. fig. 5) and another (plate I. fig, 6) similarly taken with the malachite-green screen. These are very poor photographs of Podura, and I have only chosen them because both are in the same focus, and both were taken with the full available aperture (about $\cdot 95$ ). The one taken with the violet screen is very "fuzzy, but the other is fairly sharp.

The question of using the extreme violet for purposes of photomicrography has already been taken up by Mr. Nelson, and I believe I may use his authority for saying that the lenses he used he found so imperfectly corrected for spherical aberration as to be useless. I also have worked through a number of lenses, including apochromatics, in the hope of finding one properly corrected for it, but have entirely failed to find such a lens.

I am well aware that opticians will tell me that first-rate results may now be obtained withont the use of any screen, but my experience has been that an apochromat with the malachite-green screen, which takes most lenses at their best, carries results much further than an apochromat without a screen. I would ask whether some one is not prepared to construct a lens in which everything has been sacrificed to spherical correction for the violet. If this were done we should combine the good points of a screen with the advantages of working without one, making use of rays of great resolving power on the one hand, and photographing with considerable rapidity on the other.

But the screen may even now be useful. By diluting the solution somewhat, the band widens out towards line $F$, and finally overlaps it. It is now, of course, not so monochromatic, and we should suppose would give inferior results. But we find that the spectrum obtained with the diluted solution very nearly coincides with that impressed on a bromo-iodide (ordinary) photographic plate without a screen, and takes in a portion of the spectrum covered by the malachite-green screen, for which lenses, generally speaking, are more spherically correct. 
You have before you a photograph of Podura taken in this way (plate I. fig. 7) which is not bad. But it is not nearly so good as the two following (plate I. figs. $8 a$ and $b$ ) taken with the malachite-green screen.

In concluding, I want to draw your attention to methyl-green. It will give as good results as malachite-green and transmits so little red and ultra-violet, that for all except the most exact work, it can be used without the blue glass. A cell containing a glycerin solution of methyl-green may be made up with two thin cover-glasses and a metal ring only. Such a screen is very light, very thin, and will not break with any ordinary amount of knocking about. 